\title{
The relationship between severity of ulcerative colitis and thiol-disulphide homeostasis
}

\author{
Neselioglu $\mathrm{S}^{1}$, Keske $\mathrm{PB}^{2}$, Aydin Senat $\mathrm{A}^{4}$, Yurekli $\mathrm{OT}^{3}$, Erdogan $\mathrm{S}^{4}$, Alisik $\mathrm{M}^{4}$, Ergin $\mathrm{M}^{5}$, \\ Koseoglu $\mathrm{H}^{6}$, Ersoy $\mathrm{O}^{3}$, Erel $\mathrm{O}^{1}$
}

Department of Biochemistry, Yildirim Beyazit University Faculty of Medicine, Ankara, Turkey. salim_neselioglu@hotmail.com

\begin{abstract}
OBJECTIVES: The aim of the study was to determine dynamic thiol-disulphide homeostasis in patients with ulcerative colitis, compare it with those of healthy control and to investigate the relationship between the severity of the disease and homeostasis

METHODS: A total of 78 patients and 58 healthy subjects were included in the study. Serum native thiol, total thiol and disulphide amounts were measured by using a novel automated method. Obtained results were compared and relationships were determined by correlation analysis.

RESULTS: Serum native thiol, total thiol, disulphide amounts and disulphide/native thiol percent ratio (index) were significantly lower ( $p=0.003$ for index ratio and $p<0.001$ for other parameters) in patients with ulcerative colitis than in healthy controls. Native thiol, total thiol and disulphide amounts were significantly higher ( $p$ $<0.001$ ) in patients with ulcerative colitis in remission than in patients with active ulcerative colitis and near to those of healthy control. There were significant negative correlations between the severity of the disease and thiol-disulphide homeostasis parameters $(r=-0.55, p<0.001$ for native thiol; $r=-0.64, p<0.0001$ for total thiol; $r=-0.65, p<0.001$ for disulphide and $r=-0.33, p=0.011$ for index).

CONCLUSION: The thiol-disulphide homeostasis was weakened in ulcerative colitis. Strong correlations between the activity of the disease and thiol-disulfide homeostasis indicate that homeostasis may play a role in the pathogenesis of the disease (Tab. 3, Fig. 3, Ref. 30). Text in PDF www.elis.sk.

KEY WORDS: disulphide, inflammatory bowel disease, thiol; ulcerative colitis.
\end{abstract}

\begin{abstract}
Abbreviations: SD - Standard deviation, IBD - Inflammatory bowel disease, TGF- $\beta 1$ - Transforming Growth Factor-Beta 1, IL-10 - Interleukin 10, TDH - Thiol-disulphide homeostasis, BMI - Body mass index, [SH] - Native thiol, [SH]+[SS] - Total thiol, [SS] - Disulphide, Index - Disulphide/native thiol percent ratio, $[\mathrm{SS}] /[\mathrm{SH}] \%), \mathrm{CRP}-\mathrm{C}$-reactive protein, ESR - Erythrocyte sedimentation rate, GSH - Glutathione.
\end{abstract}

\section{Introduction}

Inflammatory bowel disease (IBD) appearing as acute or subacute inflammation in the small intestine and colon, is characterized by remissions and exacerbations. Ulcerative colitis is a subgroup of IBD. Although many hypotheses are currently available, the

${ }^{1}$ Department of Biochemistry, Yildirim Beyazit University Faculty of Medicine, Ankara, Turkey, ${ }^{2}$ Department of Internal Medicine, Prof. Dr. A. İlhan Ozdemir State Hospital, Giresun, Turkey, ${ }^{3}$ Department of Gastroenterology, Yildirim Beyazit University, Faculty of Medicine, Ankara,Turkey, ${ }^{4}$ Department of Clinical Biochemistry, Ataturk Training and Research Hospital, Ankara, Turkey, ${ }^{5}$ Department of Biochemistry, 25 Aralik State Hospital, Gaziantep, Turkey, and ${ }^{6}$ Department of Gastroenterology, Hitit University, Faculty of Medicine, Çorum, Turkey

Address for correspondence: S. Neselioglu, Ankara Yildirim Beyazit University Faculty of Medicine, Ankara, Turkey.

Phone +90.3122912525 etiology of ulcerative colitis is not clear. It has been considered that genetic, infectious, immunological and environmental factors take part in the pathogenesis. However, it has also been suggested that ulcerative colitis may emerge as a consequence of an inappropriate inflammatory response to intestinal microorganisms in genetically predisposed individuals (1).

Thiols are organic compounds that possess a carbon-bonded sulfhydryl group. The antioxidants containing thiol groups such as glutathione, cysteine and n-acetylcysteine are known as antiinflammatory molecules against reactive oxygen species generating in inflammation $(2,(3,(4)$. Thiols groups can form reversible disulphide bridges by the effect of oxidants in plasma (5). The formed disulphide bridges can be reduced to thiol groups again via the antioxidant systems in the organism. Thus, dynamic thioldisulphide homeostasis (TDH) is maintained (6). TDH system has essential and significant functions in cellular mechanisms like antioxidant defence, inflammation, regulation of enzyme activities, proliferation and immunity $(7,(8)$. The TDH system measured according to novel method shows that the balance is shifted to thiol formation or disulphide formation, but in some cases, the balance is weakened. Altered TDH values have been observed in various diseases such as cancer, myocardial infarction, hypertension, diabetes mellitus, preeclampsia, and hyperemesis $(9,(10,(11,(12$, (13, (14). TDH balance has shifted to form disulphide in some diseases such as familial Mediterranean fever (15), celiac disease 
(16) and febrile seizures (17), on the other hand, the balance has turned to form thiol in basal cell carcinoma (18). Beside this, in case of uterine myoma, THD balance has been broken down (19).

The aim of the study was to analyse the TDH profile tests in patients with ulcerative colitis and to determine the relationship between the thiol-disulphide levels and clinical parameters and scores. To the best of our knowledge, this is the first study evaluating TDH system in the disease.

\section{Materials and methods}

Fifty-eight healthy controls ( 37 male; 21 female), 20 patients with ulcerative colitis in remission (11 male; 9 female) and 58 patients with active ulcerative colitis ( 38 male; 20 female) were included in this study. Among patients with active ulcerative colitis, there were 10 with mild activity, 22 with moderate activity, and 26 with severe activity.

The difference between active period and remission of ulcerative colitis was determined according to the clinical score, endoscopic score, and laboratory findings.

Active ulcerative colitis was classified as mild (1), moderate (2) and severe (3) according to Truelove Witts clinical activity index and Rachmilewitz endoscopic activity index (20, (21, (22). Exclusion criteria for the present study were determined as abdominal abscess, liver disease, chronic renal failure, pregnancy, acute viral or bacterial infection, cancer, hypertension diabetes mellitus, anti-inflammatory and vitamin medications, and active smoking. The study protocol was approved by the local ethics committee and written informed consents were received from all subjects involved in the study. Venous blood samples were collected from the subjects and centrifuged at $1500 \times \mathrm{g}$ for $10 \mathrm{~min}$. Serum samples were separated and stored at $-80{ }^{\circ} \mathrm{C}$ until analysis.

Serum native thiol ([SH]) and total thiol $([\mathrm{SH}]+[\mathrm{SS}])$ levels were measured directly with a recently developed and automatic measurement method by using an automated clinical chemistry analyzer (Roche, Cobas 501, Mannheim, Germany). Disulphide ([SS]) amount and the index ([SS] / [SH] \%) results were calculated as follows; Disulphide $=([$ total thiol-native thiol $] / 2)$ and index $=$ disulphide/native thiol $\%$ ratio.

Tab.1. Demographic characteristics and thiol-disulphide homeostasis values of healthy group and ulcerative colitis groups.

\begin{tabular}{lccc}
\hline Variable & $\begin{array}{c}\text { Healthy group } \\
\text { mean } \pm \text { SD } \\
(\mathrm{n}=58)\end{array}$ & $\begin{array}{c}\text { Ulcerative colitis } \\
\text { mean } \pm \text { SD } \\
(\mathrm{n}=78)\end{array}$ & $\mathrm{p}$ \\
\hline Native Thiol [SH] & $345.00 \pm 55.58$ & $304.71 \pm 50.14$ & $<0.001^{*}$ \\
Total Thiol [SH+SS] & $391.89 \pm 56.82$ & $340.85 \pm 56.25$ & $<0.001^{*}$ \\
Disulphide [SS] & $23.44 \pm 5.45$ & $18.07 \pm 5.74$ & $<0.001^{*}$ \\
Index** [SS]/ [SH] & $6.99 \pm 2.07$ & $5.95 \pm 1.70$ & $0.003^{*}$ \\
Age $($ years $)$ & $48.00 \pm 15.25$ & $44.29 \pm 12.94$ & $\mathrm{NS}$ \\
Male $(\mathrm{n} / \%)$ & $37(43)$ & $21(42)$ & $\mathrm{NS}$ \\
Female $(\mathrm{n} / \%)$ & $49(57)$ & $29(58)$ & $\mathrm{NS}$ \\
BMI $\left(\mathrm{kg} \mathrm{m}{ }^{-2}\right)$ & $25.26 \pm 2.28$ & $26.49 \pm 4.86$ & $\mathrm{NS}$ \\
\hline
\end{tabular}

*Indicates a significant statistical difference with $\mathrm{p}<0.05$; **Index: Disulphide/ Native thiol percent ratio, \%; All values are given in $\mu \mathrm{mol} / \mathrm{L}$ units (without index parameter)i்; BMI: Body Mass Index
Hematocritand hemoglobin weremeasured from samples collected in K2 EDTA tubes using an automatic analyzer (Sysmex XE-2100, USA) within five minutes of sampling. CRP(Siemens BN II System, Germany), ESR (Therma NE, Spain) and albumin (Roche Cobas 8000, Mannheim, Germany) were measured using commercial kits.

The data were evaluated using visual (histograms, probability plots) and statistical methods (Kolmogorov-Smirnov test and Shapiro-Wilktest) to determine whether the data were normally distributed. Descriptive analyses were presented using mean and standard deviation (mean $\pm \mathrm{SD}$ ) for the normally distributed variables. As the data were normally distributed, independent sample $t$-tests and one-way ANOVA were conducted to compare the parameters among groups. Correlation analyses were managed using Pearson's correlation. An overall 5\% type 1 error was used to infer statistical significance. Statistical analyses were performed using the SPSS software version 20 (SPSS Inc. Chicago, IL, USA). Figures were generated using GraphPad Prism (Version 6.0; GraphPad Software Inc., La Jolla California USA).

\section{Results}

Demographic characteristics and TDH values of the healthy and ulcerative colitis groups are shown in Table 1. Gender ( $\mathrm{p}=$ $0.467)$, body mass index (BMI) $(\mathrm{p}=0.172)$, and age $(\mathrm{p}=0.128)$ of the healthy and ulcerative colitis groups were not different significantly.
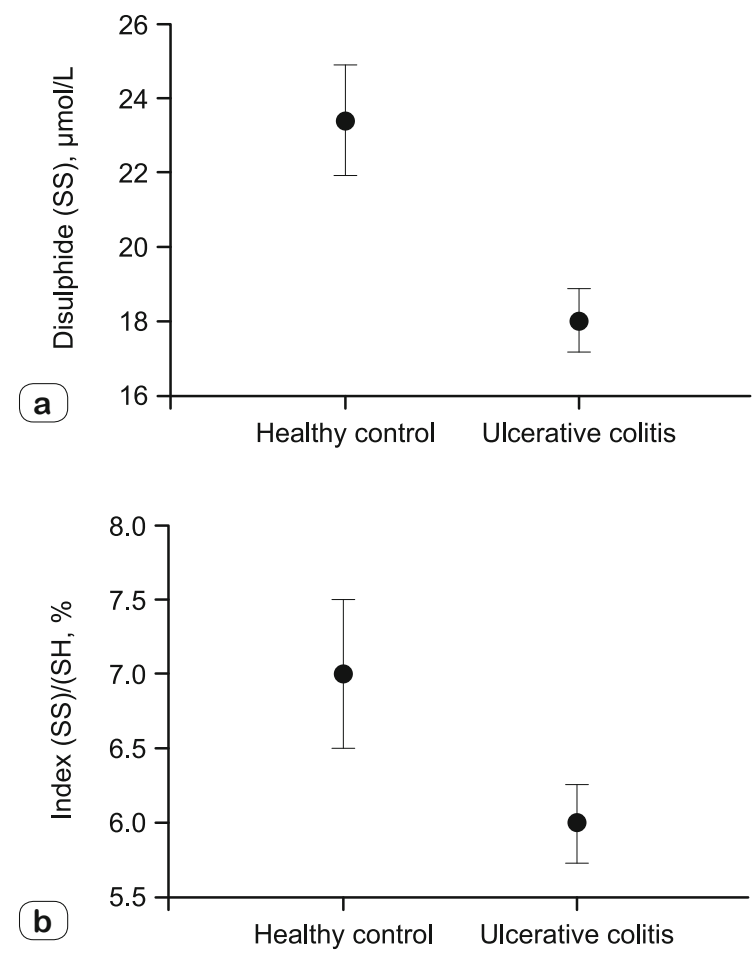

Fig. 1. Thiol-disulphide homeostasis in healthy control and ulcerative colitis. a) Serum disulphide values $(\bar{x} \pm \sigma M)$ in healthy control and ulcerative colitis, b) Serum index values $(\bar{x} \pm \sigma M)$ in healthy control and ulcerative colitis. 
Tab. 2. Thiol-disulphide homeostasis values of the healthy group, ulcerative colitis-remission group and ulcerative colitis-active group.

\begin{tabular}{|c|c|c|c|c|c|c|}
\hline Variable & $\begin{array}{l}\text { Healthy group(1) } \\
\text { mean } \pm \mathrm{SD} \\
(n: 58)\end{array}$ & $\begin{array}{l}\text { Ulcerative colitis } \\
\text { remission group (2) } \\
\text { mean } \pm \mathrm{SD} \\
(n: 20)\end{array}$ & $\begin{array}{l}\text { Ulcerative colitis } \\
\text { active group (3) } \\
\text { mean } \pm \text { SD } \\
(n: 58)\end{array}$ & ANOVA & $\begin{array}{c}\text { Comparison } \\
\text { Group }\end{array}$ & $\begin{array}{c}\text { Post hoc } \\
p \text {-value }\end{array}$ \\
\hline Native Thiol [SH] & $345.00 \pm 55.58$ & $340.85 \pm 44.00$ & $292.25 \pm 46.40$ & $<0.001 *$ & $\begin{array}{l}1 \text { vs } 2 \\
1 \text { vs } 3 \\
2 \text { vs } 3\end{array}$ & $\begin{aligned} & 0.945 \\
< & 0.001 * \\
< & 0.001 *\end{aligned}$ \\
\hline Total Thiol [SH+SS] & $391.89 \pm 56.82$ & $385.54 \pm 49.41$ & $325.44 \pm 50.18$ & $<0.001 *$ & $\begin{array}{l}1 \text { vs } 2 \\
1 \text { vs } 3 \\
2 \text { vs } 3 \\
\end{array}$ & $\begin{array}{c}0.889 \\
<0.001 * \\
<0.001 *\end{array}$ \\
\hline Disulphide [SS] & $23.44 \pm 5.45$ & $22.34 \pm 5.99$ & $16.59 \pm 4.89$ & $<0.001 *$ & $\begin{array}{l}1 \text { vs } 2 \\
1 \text { vs } 3 \\
2 \text { vs } 3 \\
\end{array}$ & $\begin{array}{c}0.704 \\
<0.001 * \\
<0.001 * \\
\end{array}$ \\
\hline Index $* *[\mathrm{SS}] /[\mathrm{SH}]$ & $6.99 \pm 2.07$ & $6.57 \pm 1.72$ & $5.74 \pm 1.66$ & $0.002 *$ & $\begin{array}{l}1 \text { vs } 2 \\
1 \text { vs } 3 \\
2 \text { vs } 3 \\
\end{array}$ & $\begin{array}{c}0.668 \\
<0.001^{*} \\
0.197\end{array}$ \\
\hline Hematocrit & $41.95 \pm 4.27$ & $39.55 \pm 3.83$ & $36.46 \pm 5.24$ & $<0.001^{*}$ & $\begin{array}{l}1 \text { vs } 2 \\
1 \text { vs } 3 \\
2 \text { vs } 3 \\
\end{array}$ & $\begin{array}{c}0.108 \\
<0.001 * \\
0.133\end{array}$ \\
\hline Albumin & $4.55 \pm 0.20$ & $4.44 \pm 0.31$ & $3.36 \pm 0.84$ & $<0.001 *$ & $\begin{array}{l}1 \text { vs } 2 \\
1 \text { vs } 3 \\
2 \text { vs } 3 \\
\end{array}$ & $\begin{aligned} & 0.789 \\
&< 0.001 * \\
&< 0.001^{*} \\
&\end{aligned}$ \\
\hline CRP & $0.54 \pm 1.08$ & $0.74 \pm 0.84$ & $4.03 \pm 3.25$ & $<0.001 *$ & $\begin{array}{l}1 \text { vs } 2 \\
1 \text { vs } 3 \\
2 \text { vs } 3 \\
\end{array}$ & $\begin{array}{c}1.000 \\
<0.001^{*} \\
<0.001 * \\
\end{array}$ \\
\hline ESR & $10.83 \pm 6.67$ & $21.55 \pm 15.52$ & $44.50 \pm 32.57$ & $<0.001 *$ & $\begin{array}{l}1 \text { vs } 2 \\
1 \text { vs } 3 \\
2 \text { vs } 3\end{array}$ & $\begin{array}{c}0.025^{*} \\
<0.001 * \\
<0.001 *\end{array}$ \\
\hline
\end{tabular}

*indicates a significant statistical difference with $\mathrm{p}<0.05,{ }^{*}$ Index: Disulphide/Native thiol percent ratio, $\%$.

All values are given in $\mu \mathrm{mol} / \mathrm{L}$ units (without index parameter)

The present study compared the groups of ulcerative colitis in remission period and ulcerative colitis in active period to healthy controls by measuring parameters of TDH (native thiol, total thiol, disulphide, and index) and routine laboratory tests. Additionally, the relationship between the severity of disease and TDH parameters was evaluated. TDH parameters were significantly decreased in patients with ulcerative colitis compared to healthy control group (Tab. 1, Fig. 1a, b). In a similar manner, TDH parameters were significantly decreased in active ulcerative colitis, while there was no significant difference between ulcerative colitis in remission and healthy control group. Except for index parameter, TDH parameters were significantly decreased in ulcerative colitis in active period group compared to those in ulcerative colitis in remission group. While hemoglobin, hematocrit, and albumin levels were significantly low, ESR and CRP levels were significantly high in ulcerative colitis in active period group compared to healthy control
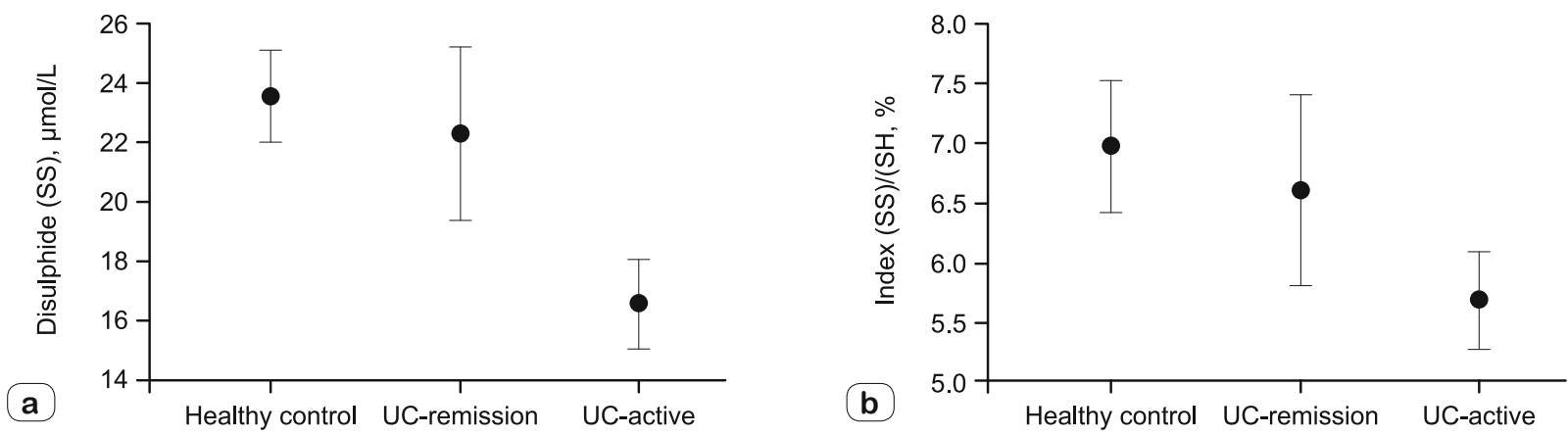

Fig. 2. Thiol-disulphide homeostasis in healthy control, ulcerative colitis-remission and ulcerative colitis-active. a) Serum disulphide values ( $\bar{x} \pm$ $\sigma \mathrm{M})$ in healthy control, ulcerative colitis-remission and ulcerative colitis active, b) Serum index values ( $\bar{x} \pm \sigma \mathrm{M})$ in healthy control, ulcerative colitis-remission and ulcerative colitis-active. 
Tab. 3. The relationship between the disease severity and thiol-disulphide homeostasis parameters.

\begin{tabular}{|c|c|c|c|c|}
\hline & $\begin{array}{c}\text { Native Thiol } \\
{[\mathrm{SH}]}\end{array}$ & $\begin{array}{c}\text { Total Thiol } \\
{[\mathrm{SH}+\mathrm{SS}]}\end{array}$ & $\begin{array}{c}\text { Disulphide } \\
{[\mathrm{SS}]}\end{array}$ & $\begin{array}{c}\text { Index** } \\
{[\mathrm{SS}] /[\mathrm{SH}]}\end{array}$ \\
\hline \multicolumn{5}{|c|}{ Clinical Score } \\
\hline $\mathrm{p}$ & $<0.001^{*}$ & $<0.001^{*}$ & $<0.001^{*}$ & $0.011 *$ \\
\hline $\mathrm{r}$ & -0.55 & -0.64 & -0.65 & -0.33 \\
\hline
\end{tabular}
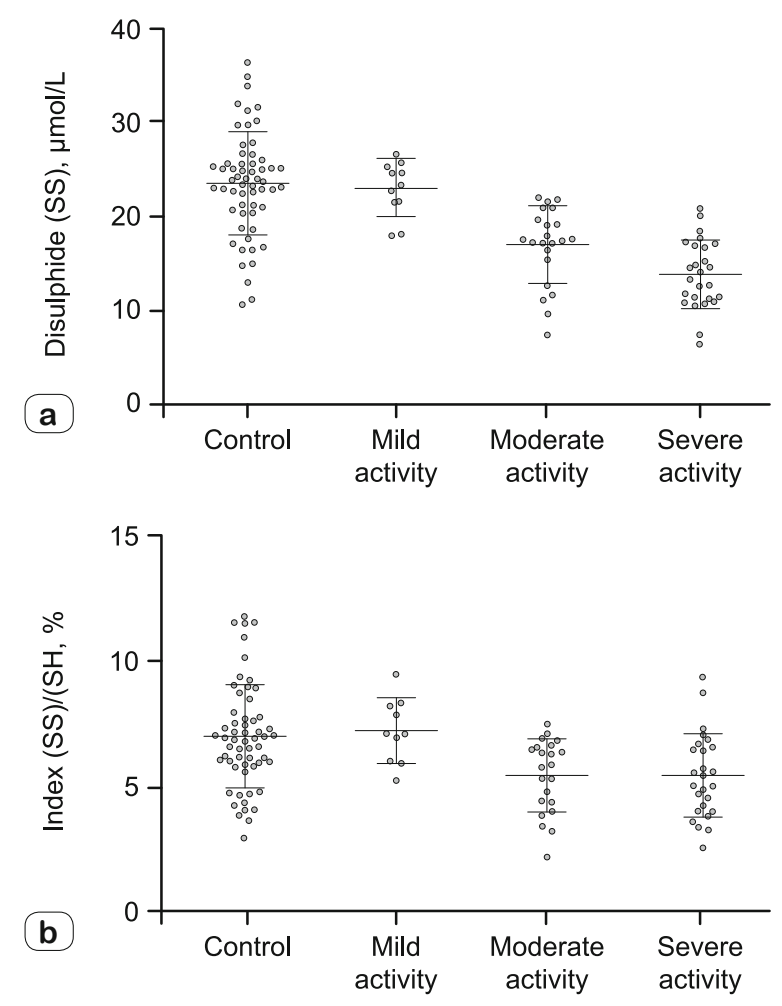

Fig. 3. The relationship between the disease severity and thiol-disulphide homeostasis parameters. a) The relationship between serum disulphide levels and disease severity, b) The relationship between serum index levels and disease severity.

group (Tab. 2, Fig. 2a, b). Additionally, the correlation between Truelove Witts Clinical score, indicating disease severity, and TDH parameters (Tab. 3, Fig. 3 a, b) was significantly negative.

\section{Discussion}

Physiologically, native thiol, disulphide, and total thiol are in a balance. This system also known as TDH is affected by various situations such as oxidation and reduction reactions. Reversible disulphide bonds are formed via oxidation reactions of thiol groups. Formed disulphide bonds are converted through reduction to thiol groups again. Thus, dynamic TDH is sustained (23). TDH system can provide information about the shift to disulphide bond formation or thiol group formation. In addition, TDH also can provide data about disrupted, weakened and strengthened situation in homeostasis. Before the novel TDH assay, it has been shown that only reduced thiol levels were determined in studies (24, (25, (26). Only a single side of this bi-directional homeostasis system has been measured in these studies. But, in our study, the levels of parameters forming the TDH (native thiol, total thiol, disulphide, and index) are measured both individually and totally with a novel method. Thus, the TDH status can be evaluated cumulatively.

Ulcerative colitis is a chronic inflammatory disease with unclear etiology. Various theories such as genetic, immunologic, environmental factors, the role of microorganisms in the intestinal flora, and oxidative stress have been proposed to explain the pathophysiological mechanisms (1). We thought that TDH parameters can contribute to pathophysiological mechanisms of disease.

Glutathione (GSH) is the most important intracellular antioxidant. The thiol moiety of GSH is important in its antioxidant function. GSH is necessary for the function and structural integrity of the gut; mice with deficiency of GSH demonstrate serious deformations in the jejunum and colonic mucosa $(27,(28,(29)$. Cysteine and cystine (formed from two cysteine molecules) are rate-limiting precursors of glutathione synthesis. The thiol group of cysteine is a strong scavenger of reactive oxygen species and could be readily depleted due to oxidation in the inflamed gut. As these amino acids are decreased in ulcerative colitis, intracellular glutathione synthesis is reduced (28). Thus, thiol-containing compounds can be expected to decline in plasma. In this study, native thiol, total thiol, and disulphide were significantly decreased as expected, compared with healthy control group and patients with ulcerative colitis (Tab. 1, Fig. 1 a, b).

When patients with ulcerative colitis in active and remission periods were compared in terms of TDH system, patients in remission period did not differ significantly from healthy control group. Remission is a condition of disappearance of symptoms and realization of mucosal healing in the endoscopic examination (30). Namely, patients with ulcerative colitis in remission tend to be similar to healthy subjects and recovery. In our study, TDH generated by native thiol, total thiol and disulphide in patients in remission period did not differ from those in healthy control group (Tab. 2, Fig. 2 a, b). These results explain why there was no statistically significant difference between the two groups. However native thiol, total thiol, and disulphide were decreased significantly in patients with active ulcerative colitis (Tab. 2, Fig. $2 \mathrm{a}, \mathrm{b})$. This situation can be explained by the decrease in intracellular glutathione synthesis in the inflamed gut. Depending on this, thiol-containing compounds in plasma may be reduced (30).

TDH system which is a dynamic balance is based on a thioldisulphide exchange reaction. But, in this study, the amounts of both thiol groups and disulphide bonds are decreased (Tabs 1 and 2). Namely, two sides constituting the thiol-disulphide balance are also decreased. We believe that the reason for decreased disulphide bonds may lie in the decrease in thiol groups transformation to disulphide bonds. As a result of this, TDH system is not shifted to the thiol group formation or disulphide bond formation, and the system is weakened. 
498-502

We found a significant negative correlation between TDH parameters and severity of ulcerative colitis disease (Tab. 3, Fig. $3 \mathrm{a}, \mathrm{b})$. According to the results of this correlation, native thiol, total thiol, disulphide, and index seem to play an important role in the clinical course of ulcerative colitis. We think that the prediction of clinical relapse in ulcerative colitis would be possible with advanced research.

$\mathrm{n}$ conclusion, the present study shows that the TDH system in patients with ulcerative colitis is weakened or broken. According to our results, we think that TDH system tests could provide good monitoring parameters for the clinical course of ulcerative colitis because TDH parameters have a significant correlation with the severity of ulcerative colitis and there is a significant difference between patients in active period, whereas there is no significant difference between patients in remission period compared to healthy control group.

\section{References}

1. Boirivant M, Cossu A. Inflammatory bowel disease. Oral Dis 2012; 18 (1): 1-15.

2. Kolgelier S, Ergin M, Demir LS, Inkaya AC, Demir NA, Alisik M et al. Impaired thiol-disulphide balance in acute brucellosis. Jpn J Infect Dis 2017; 70 (3): 258-262.

3. Yasar M, Erdi I, Kaya B. The preventive effects of atorvastatin and $\mathrm{N}$-acetyl cysteine in experimentally induced ischemia-reperfusion injury in rats. Bratisl Lek Listy 2018; 119 (3): 167-174.

4. Sen CK, Packer L. Thiol homeostasis and supplements in physical exercise. Am J Clin Nutr 2000; 72 (2): 653S-669S.

5. Cremers CM, Jakob U. Oxidant sensing by reversible disulfide bond formation. J Biol Chem 2013; 288 (37): 26489-26496.

6. Jones DP, Liang Y. Measuring the poise of thiol/disulfide couples in vivo. Free Radic Biol Med 2009; 47 (10): 1329-1338.

7. Biswas S, Chida AS, Rahman I. Redox modifications of protein-thiols: emerging roles in cell signaling. Biochem Pharmacol 2006; 71 (5): 551-564.

8. Circu ML, Aw TY. Reactive oxygen species, cellular redox systems, and apoptosis. Free Radic Biol Med 2010; 48 (6): 749-762.

9. Dirican N, Dirican A, Sen O, Aynali A, Atalay S, Bircan HA et al. Thiol/disulfide homeostasis: A prognostic biomarker for patients with advanced non-small cell lung cancer? Redox Rep 2016; 21 (5): 197-203.

10. Matteucci E, Giampietro $\mathbf{O}$. Thiol signalling network with an eye to diabetes. Molecules 2010; 15 (12): 8890-8903.

11. Kundi H, Ates I, Kiziltunc E, Cetin M, Cicekcioglu H, Neselioglu $\mathrm{S}$ et al. A novel oxidative stress marker in acute myocardial infarction; thiol/disulphide homeostasis. Am J Emerg Med 2015; 33 (11): 1567-1571.

12. Ateş I, Ozkayar N, Altay M, Yilmaz FM, Topçuoğlu C, Alişik M et al. Is disulphide/thiol ratio related to blood pressure in masked hypertension? Clin Exp Hypertens 2016; 38 (2): 150-154.

13. Ozler S, Erel O, Oztas E, Ersoy AO, Ergin M, Sucak A et al. Serum thiol/disulphide homeostasis in preeclampsia. Hypertens Pregnancy 2015; 34 (4): 474-485.
14. Ergin M, Cendek BD, Neselioglu S, Avsar AF, Erel O. Dynamic thiol-disulfide homeostasis in hyperemesis gravidarum. J Perinatol 2015; 35 (10): 788-792.

15. Omma A, Sandikci SC, Kucuksahin O, Alisik M, Erel O. Can the Thiol/Disulfide Imbalance Be a Predictor of Colchicine Resistance in Familial Mediterranean Fever? J Korean Med Sci 2017; 32 (10): 1588-1594.

16. Kaplan M, Ates I, Yuksel M, Ozderin OY, Alisik M, Erel O et al. Thiol/disulphide homeostasis in celiac disease. World J Gastrointest Pharmacol Ther 2017; 8 (2): 120-126.

17. Elmas B, Erel O, Ersavas D, Yurumez Y. Thiol/disulfide homeostasis as a novel indicator of oxidative stress in children with simple febrile seizures. Neurol Sci 2017; 38 (11): 1969-1975.

18. Demirseren DD, Cicek C, Alisik M, Demirseren ME, Aktaş A, Erel O. Dynamic thiol/disulphide homeostasis in patients with basal cell carcinoma. Cutan Ocul Toxicol 2017; 36 (3): 278-282.

19. Eroglu S, Haskul I, Aziz V, Yurtcu E, Karatas F, Neselioglu S et al. Dynamic thiol/disulphide homeostasis in patients with Uterine Myoma. Eur J Obstet Gynecol Reprod Biol 2017; 216: 24-26.

20. Önal I, Beyazit Y, Şener B, Savuk B, Özer ED, Sayilir A et al. The value of fecal calprotectin as a marker of intestinal inflammation in patients with ulcerative colitis. Turk J Gastroenterol 2011; 23 (5): 509-514.

21. Lichtiger S, Present D. Preliminary report: cyclosporin in treatment of severe active ulcerative colitis. Lancet 1990; 336 (8706): 16-19.

22. Rachmilewitz DO. Coated mesalazine (5-aminosalicylic acid) versus sulphasalazine in the treatment of active ulcerative colitis: a randomised trial. Bmj 1989; 298 (6666): 82-86.

23. Erel O, Neselioglu S. A novel and automated assay for thiol/disulphide homeostasis. Clin Biochem 2014; 47 (18): 326-332.

24. Bouzid D, Gargouri B, Mansour RB, Amouri A, Tahri N, Lassoued S et al. Oxidative stress markers in intestinal mucosa of Tunisian inflammatory bowel disease patients. Saudi J Gastroenterol 2013; 19 (3): 131.

25. Bitiren M, Karakilcik AZ, Zerin M, Ozardali I, Selek S, Nazligül Y et al. Protective effects of selenium and vitamin E combination on experimental colitis in blood plasma and colon of rats. Biol Trace Elem Res 2010; 136 (1): 87-95.

26. Aleisa AM, Al-Rejaie SS, Abuohashish HM, Ola MS, Parmar MY, Ahmed MM. Pretreatment of Gymnema sylvestre revealed the protection against acetic acid-induced ulcerative colitis in rats. BMC Complement Altern Med 2014; 14 (1): 49.

27. Satoh H, Sato F, Takami K, Szabo S. New ulcerative colitis model induced by sulfhydryl blockers in rats and the effects of antiinflammatory drugs on the colitis. Jpn J Pharmacol 1997; 73 (4): 299-309.

28. Sido B, Hack V, Hochlehnert A, Lipps H, Herfarth C, Dröge W. Impairment of intestinal glutathione synthesis in patients with inflammatory bowel disease. Gut 1998; 42 (4): 485-492.

29. Yilmaz CD, Bircan F, Pasaoglu O, Turkozkan N. The effects of resveratrol on hepatic oxidative stress in metabolic syndrome model induced by high fructose diet. Bratisl Lek Listy 2018; 119 (1): 36-40.

30. Rogler G, Vavricka S, Schoepfer A, Lakatos PL. Mucosal healing and deep remission: what does it mean. World J Gastroenterol 2013; 19 (43): 7552-7560. 